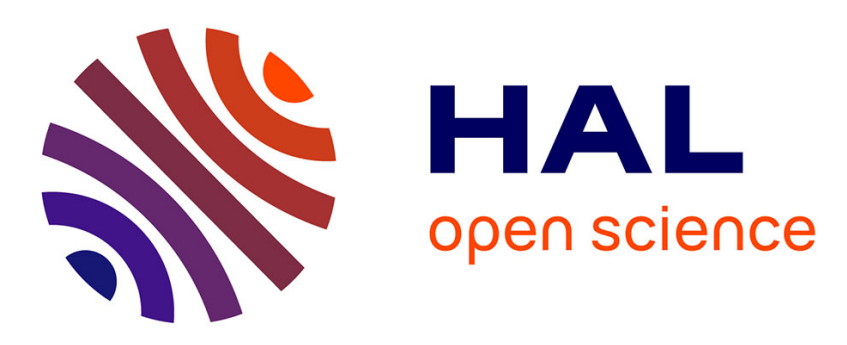

\title{
Multi-objective Approach and Model for Transfer Line Reconfigurations
}

\author{
F. Makssoud, O. Battaïa, Alexandre Dolgui
}

\section{To cite this version:}

F. Makssoud, O. Battaïa, Alexandre Dolgui. Multi-objective Approach and Model for Transfer Line Reconfigurations. Lyes Benyoucef. Reconfigurable Manufacturing Systems: From the Design to Implementation, Springer, pp.193-208, 2020, Springer Series in Advanced Manufacturing, 978-3-03028784-9. 10.1007/978-3-030-28782-5_10 . hal-03170898

\section{HAL Id: hal-03170898 \\ https://hal.science/hal-03170898}

Submitted on 25 May 2021

HAL is a multi-disciplinary open access archive for the deposit and dissemination of scientific research documents, whether they are published or not. The documents may come from teaching and research institutions in France or abroad, or from public or private research centers.
L'archive ouverte pluridisciplinaire HAL, est destinée au dépôt et à la diffusion de documents scientifiques de niveau recherche, publiés ou non, émanant des établissements d'enseignement et de recherche français ou étrangers, des laboratoires publics ou privés. 


\title{
Chapter \# \\ Multi-objective approach and model for transfer line reconfigurations
}

\author{
F. Makssoud, O. Battaïa, A. Dolgui
}

Fatme Makssoud, Lebanese University, Saida, Lebanon South fatme.makssoud@gmail.com

Olga Battaïa, KEDGE Business School, Talence, France

olga.battaia@kedgebs.com

Alexandre Dolgui, IMT Atlantique, LS2N-CNRS, Nantes, France alexandre.dolgui@imt-atlantique.fr

\begin{abstract}
The problem of reconfiguration appears also for the transfer lines that are designed for mass production of a single product. When a new product should be produced at an existing transfer line, it is necessary to reconfigure it. This is costly, thus the reconfiguration process should be optimized. This chapter presents a multiobjective mathematical model for such a problem and develops a goal programming approach to solve it. The results of computational experiments are reported.
\end{abstract}

Keywords Transfer lines, Reconfiguration, Multi-objective optimization, Goal programming

\section{Introduction}

Global competition causes fluctuations in product demand and requires more frequent modifications of product characteristics. As a consequence, the production systems have to be timely adapted to new products and production requirements. The manufacturing systems used for mass production as transfer lines are usually not designed to be reconfigured (Guschinskaya and Dolgui, 2009). Because of their rigid architecture, the reconfiguration of such systems is costly and a source of new investments and presents an important issue for manufacturers. However, this option may remain more interesting in terms of time and budget comparing to the installation of new lines. In the automotive industry, for example, in the Groupe PSA, each transfer line is reconfigured at least once every 7 years. In August of each year, the transfer lines which need reconfiguration are stopped and reconfigured. However, few studies in the literature dealt with the reconfiguration of transfer lines (Makssoud et al., 2015). Moreover, the majority of existing work was devoted to the case of manual assembly in which the use of flexible human resources makes the reconfiguration feasible in relatively short time. Unfortunately, this is not the case for the automated transfer lines where the involvement of the equipment manufacturer is usually required in order to replace the obsolete machining modules with new ones adapted to new product 
characteristics or production requirements. Obviously, the whole line has to be stopped during the reconfiguration period. For these reasons, the manufacturers are looking for reducing the reconfiguration cost and time.

The reconfiguration of automated transfer lines consists of the following: a reconfiguration team of the original equipment manufacturer has to decide which equipment can be reused in the reconfigured line and what new equipment has to be installed in order to meet new product and production requirements. The compatibility constraints between new and old equipment have to be taken into account.

This chapter presents a multi-objective mathematical model for such reconfiguration problems and develops goal programming techniques to solve them.

\section{Design and optimization of transfer lines}

Transfer lines are usually used and designed for mass production of a single product (Dolgui and Proth, 2006). They consist of a number of linearly ordered workstations linked by an automated material handling device. The products are released at the beginning of the line with a constant frequency imposed by the objective cycle time. All stations work in parallel on the products that move from a workstation to another in a paced way.

Each workstation is equipped with several spindle heads that are activated sequentially. An example of workstation equipment is presented in Fig. 1. A spindle head is used for performing a set of operations in parallel, since it may carry multiple tools activated simultaneously by the force of a common engine. A set of operations executed by a spindle head is referred to as a block.

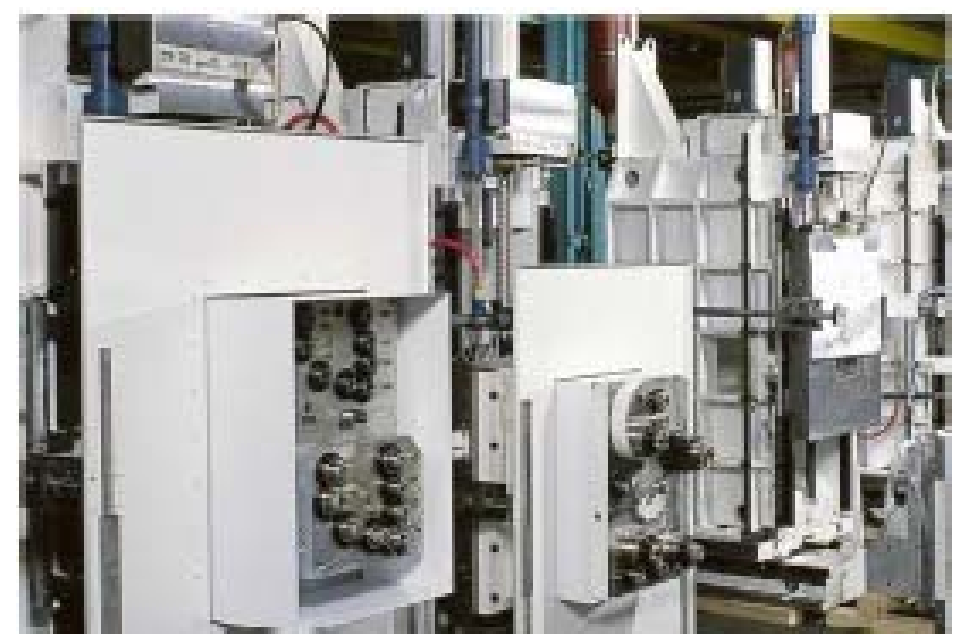

Figure 1. Multi-spindle equipment (PCI SCEMM, Groupe PSA)

Fig. 2 presents an example of a transfer line for performing 16 operations that consists of 3 workstations and 6 blocks. Here, when the part is loaded on workstation 1, first, operations 1 and 3 are performed simultaneously (block 1 ), then operation 2 is executed on the part. After the time interval equal to the line cycle time, the part is moved to 
workstation 2 where two blocks of operations are executed sequentially. We consider here that the time needed to process a block is equal to the time of the longest operation included in it. The workstation time is the sum of processing times of its blocks and the line cycle time is the maximum of workstation times.

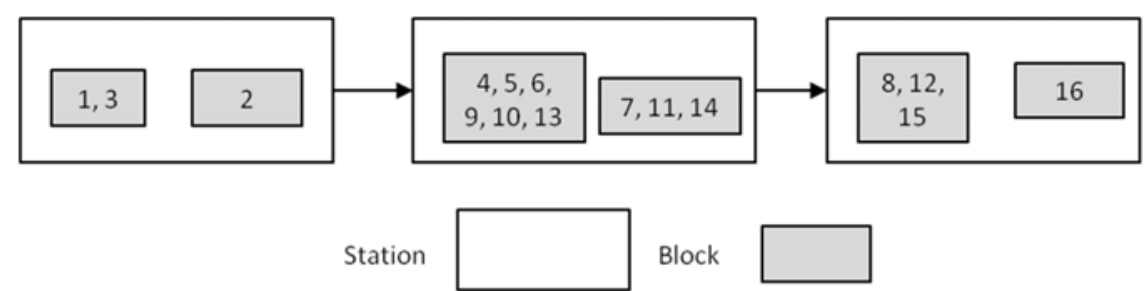

Figure 2. An example of task assignment in a transfer line

When a new line is designed, the three following cases are usually considered (Battaïa et al., 2014):

1. There exist several types of equipment and task processing time as well as cost (if considered) for each task depends on which piece of equipment it is executed with. The pieces of each equipment type are available in unlimited quantity (Bukchin and Tzur, 2000; Gadidov and Wilhelm, 2000; Kimms, 2000; Pekin and Azizoglu, 2008; Essafi et al., 2010; Li et al., 2011; Ozdemir and Ayag, 2011; Yoosefelahi et al., 2012).

2. The set of available equipment is limited and different constraints between equipment exist and have to be taken into account (Belmokhtar et al., 2006; Delorme et al., 2012). In this case, if one of these unique resources is allocated to a workstation, then it becomes unavailable for other workstations.

3. The compatibility between tasks is modelled by means of exclusion and inclusion constraints which indicate if some tasks can be executed with the same equipment or not. The equipment to be used in the line is designed (created) on the basis of the obtained task assignment (Dolgui et al., 2006ab; Guschinskaya et al., 2008; Dolgui et al., 2009; Guschinskaya et al., 2009; Guschinskaya et al., 2011; Battaïa et al., 2012ab; Osman and Baki, 2014).

The problem considered here is a mixture of the two latter cases. On the one hand, the available equipment can be reused for proceeding some existing or new operations, on the another hand, new equipment should be designed for the operations that cannot be performed with available resources. While grouping the operations into blocks and assigning them to the workstations, the following technological constraints have to be taken into consideration:

- Precedence constraints are usually expressed with a digraph $G=(N, D)$ where $N$ is the set of all operations to be assigned and $(i, j) \in D$ means that operation $j$ cannot be started before the end of operation $i$, but operations $i$ and $j$ can be performed in the same block if no block exclusion constraint forbids it. 
- Block exclusion constraints contain the groups of operations that cannot be grouped to the same block. These constraints are represented by family $E B$ of subsets from $N$ such that each subset $e \in E B$ cannot belong to the same block.

- Workstation exclusion constraints contain the groups of operations that cannot be assigned to the same workstation. These constraints are represented by family $E S$ of subsets from $N$ such that each subset $e \in E S$ cannot be assigned to the same workstation.

- Inclusion constraints force the assignment of certain operations to the same workstation. These constraints are represented by family $I S$ which is a family of subsets from $N$ such that all operations of the same subset $e \in I S$ must be assigned to the same workstation.

For example, for the line presented in Fig. 2, the following constraints may exist:

- $E S=\{\{2,5\},\{2,9\},\{2,13\},\{3,4\},\{3,5\},\{3,9\},\{3,13\}\}$;

- $E B=\{\{1,2\},\{2,3\},\{6,7\},\{7,8\},\{10,11\},\{11,12\},\{13,14\},\{14,15\},\{8,16\}\}$;

- IS $=\{\{7,11\}\}$.

The precedence constraints are given in Figure 3.

More details on such constraints as well as on pre-processing treatments on them can be found in (Battaïa and Dolgui, 2012) and (Battaïa et al., 2013).

The design objective is often to minimize the total line cost (Battaïa et al., 2012ab), however, other performance criteria can be also considered, for example the robustness of the obtained solution (Gurevsky et al., 2012; Gurevsky et al., 2013a; Gurevsky et al., 2013b; Rossi et al., 2016; Sotskov et al., 2019).

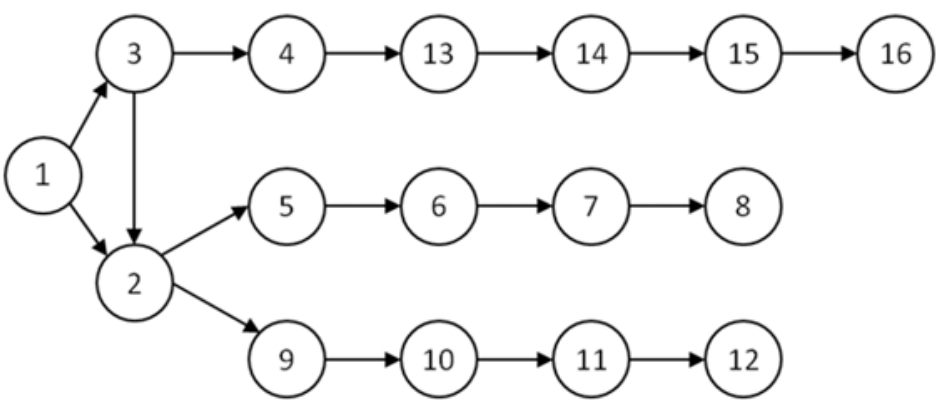

Figure 3. Precedence graph for the example given in Fig. 2

In contrast, the reconfiguration problem is characterized by a different objective which is to minimize the cost incurred by the modifications of the line. This cost can be reduced by reusing the existing equipment as much as possible. In the general case, the workstations and spindle heads (used for performing blocks of operations) can be reused under the following constraints:

- Operations can be deleted and new operations can be added to an existing spindle head (block) if all compatibility constraints among machining operations are respected.

- Existing spindle heads can be removed from their initial workstation and installed at any workstation of the line. 
For instance, in the line given in Fig. 2, if operations $\{9,10,11,12\}$ become obsolete and new operations $\{17,18,19,20\}$ are required with the new precedence constraints given in Fig. 4 and the following technological constraints:

- $\mathrm{ES}=\{\{2,5\},\{2,17\},\{3,4\},\{3,5\},\{3,13\},\{3,17\}\}$;

- $\mathrm{EB}=\{\{1,2\},\{2,3\},\{6,7\},\{7,8\},\{13,14\},\{13,18\},\{13,19\},\{14,15\},\{14$, $17\},\{14,18\},\{14,19\},\{15,16\},\{15,17\},\{15,18\},\{15,19\},\{17,18\},\{18,19\}$, $\{19,20\}\}$;

- $\mathrm{IS}=\emptyset$.

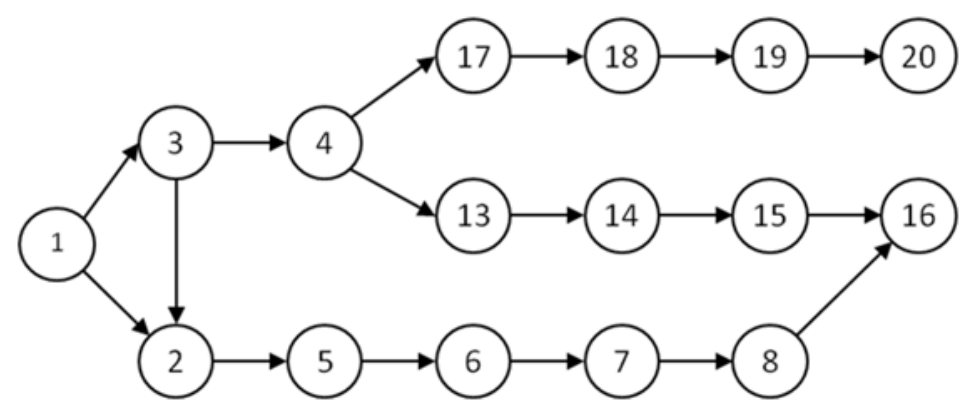

Figure 4. New precedence graph

Then the transfer line given in Fig. 2 can be reconfigured as shown in Fig. 5.

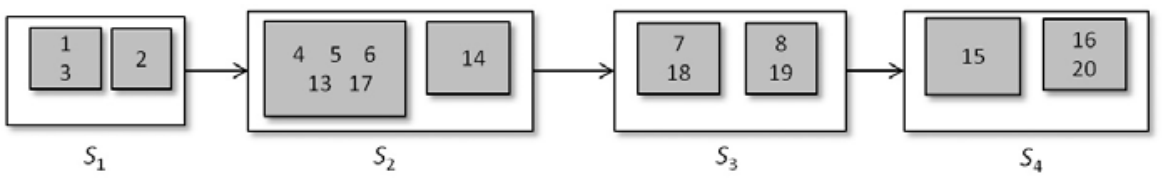

Figure 5. Transfer line after reconfiguration

As it can be seen, 3 workstations and 6 blocks have been reused and a new workstation and 2 new blocks were installed in order to satisfy the new production requirements.

For example, Altemeier et al. (2010) considered an assembly line reconfiguration problem in the context of a make-to-order production process with a huge product variety. The goal was to minimize production costs by reassigning tasks between workstations. Corominas et al. (2008) addressed a rebalancing problem at a motorcycle-assembly plant. The rebalancing problem was to reassign tasks among permanent and temporary workers while minimizing the number of temporary workers required. Gamberini et al. $(2006 ; 2009)$ dealt with the rebalancing problems in singlemodel manual assembly lines, where workers should be retrained to perform new tasks. They used two separate objective functions concerning expected completion costs and the degree of similarity between initial and new task assignments.

As it can be noted, the rebalancing problem for an assembly line mostly concerns the reassignment of tasks to workers without taking into account the reconfiguration of 
the equipment used. However, in highly automated lines, as the transfer lines considered in this paper, the reconfiguration problem is focused on the readjustment of the equipment. To reduce the investment costs, the users aim to reuse the available equipment as much as possible. The existence of compatibility constraints between new operations to be performed and existing facilities makes the reconfiguration problem hard and combinatorial for the decision makers. At the same time, the models and methods proposed for the initial design of such systems cannot be applied directly for the reconfiguration problem, since they do not take into account the possible reuse of the existing equipment.

Therefore, the decision makers need new efficient solution methods for the reconfiguration problem. It can be noted that this problem is a generalization of simple assembly line balancing problem (SALBP) (Dolgui and Proth, 2010). As for SALBP, the goal is to assign operations from a given set to a number of workstations under precedence and cycle time constraints. However, additional constraints have to be taken into account and different objectives have to be considered. A first Mixed Integer Program (MIP) for the reconfiguration problem of transfer lines was proposed in (Makssoud et al., 2014). However, this model is based on the assumption that the benefit of the reutilisation of an equipment can be assessed. Since it is not always possible in practice, the model presented in this chapter does not need this information.

For this new combinatorial optimisation problem, this chapter formulates a mathematical model and proposes a goal programming approach to solve it.

\section{Goal programming}

Goal programming (GP) is a technique often used in multi-objective optimisation to simultaneously satisfy a number of design goals. The concept of GP is to introduce extra auxiliary variables called deviations which represent the distance between the target values of goals and the realized results. Two kinds of deviations are considered, under-achievement of the goal as represented by negative deviation (d-) and overachievement of the goal as represented by positive deviation $(\mathrm{d}+)$ (Kim and Emery, 2000). Each goal is expressed as a linear equation with deviations.

GP model consists of two sets of constraints, system constraints and goal constraints. System constraints are formulated following the concept of linear programming, whilst goal constraints determine the deviations from target values.

In the literature, the goal programming has been already successfully applied to the line balancing problems mostly in the assembly environment.

First, a zero-one goal programming model for the assembly line balancing problem was developed by Deckro and Rangachari (1990). It considered varying operational requirements, such as zoning, sequencing, idle time, cycle time and costs. Gokcen and Erel (1997) extended this model by taking into account the assembly of several product models in the same line (mixed-model assembly line).

A goal programming model for the simple U-line balancing problem with multiple objectives was presented in (Gokcen and Agpak, 2006). It was used for simultaneously optimizing such conflicting goals as the number of workstations, the sum of processing times of operations which are assigned to any workstation and the total number of operations which are assigned to each workstation. The same model but for the case where the goal values are imprecise, vague, or uncertain was treated by Toklu and Ozcan (2008) by a fuzzy goal programming approach. This problem has also been considered by Kara et al. (2009) but with different fuzzy goals, namely the number of 
workstations and the cycle time. Agpak and Gokcen (2007) used the goal programming techniques for the stochastic straight and U-type line balancing problem in order to equalize the workloads between workstations with respect to variances and/or mean times. Ozcan et al. (2009) developed a pre-emptive goal programming model for precise goals and a fuzzy goal programming model for two-sided assembly line balancing problem. The number of mated-stations (pairs of two directly facing stations), cycle time and the number of operations assigned per station were considered as goals.

Choi (2009) used the goal programming approach for balancing assembly lines in terms of processing time and physical workload assigned to each worker.

Kara et al. (2010) proposed two goal programming approaches to balance parallel assembly lines with precise and fuzzy goals. Three conflicting goals, namely number of workstations, cycle time, and number of operations assigned to a workstation were optimised in crisp and fuzzy environments. Kara et al. (2011) developed two preemptive goal programming models, one with precise and the other with fuzzy goals to balance mixed-model assembly lines for model mixes having precedence conflicts and duplicable common operations. Minimizing the number of workstations, the cycle time and the total cost required to duplicate common operations were used as goals.

The conducted studies showed that the goal programming approaches provide flexibility for decision makers to balance assembly lines based on their decision environments and preferred priorities. To the best of our knowledge, this approach has not been applied yet for transfer line balancing or reconfiguration problems.

\section{Problem statement}

\subsection{Definitions}

The notations used in this section are summarized as follows:

- Indices

$k \quad$ Index of a workstation, $k=1, \ldots, m$

$q \quad$ Index of a block in the new line

$q_{0} \quad$ Maximal possible value of $q$

$n_{0} \quad$ Maximal number of blocks per workstation

$m_{0} \quad$ Maximal authorized number of workstations

$l \quad$ Index of a block in the initial line

$l_{0} \quad$ Maximal possible value of $l$

- Sets

$N \quad$ Set of the operations that are needed for machining the new part

$N^{\prime} \quad$ Set of "old" operations that remain for the new part

$\operatorname{PredD}(j)$ Set of direct predecessors of $j \in N$

$B(k) \quad$ Set of block indices for workstation $k$

$Q(j) \quad$ Set of block indices q where operation $j$ can be assigned

$K(j) \quad$ Set of workstation indices $k$ where operation $j$ can be assigned 
$e \quad$ Set of operations to represent an element of $I S, E S$ or $E B$

$N_{l} \quad$ Set of operations assigned to block $l$ in the initial solution

- Times

$t_{j} \quad$ Processing time for operation $j \in N$

$T_{0} \quad$ Maximal line cycle time (defines the line throughput)

$\tau^{b} \quad$ Auxiliary time needed for processing a block (activation of a spindle head)

$\tau^{s} \quad$ Auxiliary time needed for loading/unloading the part on a workstation

\section{- Decision variables}

$X_{j q} \quad=1$, if operation $i$ is assigned to block $q$ in the new line configuration, and 0 , otherwise.

$B_{l q} \quad=1$, if an existing bloc 1 is assigned to bloc $\mathrm{q}$ in the new line configuration, and 0 , otherwise.

$Y_{q} \quad$ Auxiliary variable that indicates if block q exists in the new line configuration.

$\mathrm{Z}_{k} \quad$ Auxiliary variable that indicates if workstation $\mathrm{k}$ exists in the new line configuration.

$F_{q} \quad$ Auxiliary real variable used for calculating block processing time, $F_{q} \in\left[0, T_{0}\right.$ - $\left.\tau^{s}\right], q=1,2, \ldots, q_{0}$

\subsection{Basic constraints}

Each operation must be assigned to exactly one block from $Q(j)$ :

$\sum_{q \in Q(j)} X_{j q}=1 ; j \in N$;

Precedence constraints:

$\sum_{q^{\prime} \in Q(i)} q^{\prime} X_{i q^{\prime}} \geq \sum_{q \in Q(j)} q X_{j q} ; \quad i \in \operatorname{PredD}(j) ; j \in N$;

Inclusion constraints:

$\sum_{q \in Q(i) \cap B(k)} X_{i q}=\sum_{q \in Q(j) \cap B(k)} X_{j q} ; i, j \in e ; e \in I S ; k \in K(i) ;$

Block exclusion constraints:

$\sum_{j \in e} X_{j q} \leq|e|-1 ; e \in E B ; q \in \bigcap_{j \in e} Q(j)$;

Workstation exclusion constraints:

$\sum_{j \in e} \sum_{B(k) \cap Q(j)} X_{j q} \leq|e|-1 ; e \in E S ; k \in \bigcap_{j \in e} K(j)$; 
Block working time is greater or equal to the processing times of the operations assigned to it (taking into account $\tau^{b}$ ):

$$
F_{q} \geq\left(t_{j}+\tau^{b}\right) X_{j q}, j \in N, q \in Q(i) ;
$$

Workstation working time has to respect the cycle time constraint:

$$
\sum_{q \in B(k)} F_{q} \leq T_{0}-\tau^{s}, k=1,2, \ldots, m_{0}
$$

A block $q$ is created, if at least one operation is assigned to it:

$$
Y_{q} \geq X_{j q}, j \in N, q \in Q(j) \text {; }
$$

A workstation $k$ is created if at least one block is assigned to it:

$$
Z_{k} \geq Y_{q}, k=1,2, \ldots, m_{0}, q=(k-1) n_{0}+1
$$

A block $q$ can be created at workstation $k$ if and only if block $q-1$ exists already for this workstation:

$Y_{q-1}-Y_{q} \geq 0 ; q \in B(k) \backslash\left\{(k-1) n_{0}+1\right\} ; k=1,2, \ldots, m_{0} ;$

A workstation $k$ can be created if and only if workstation $k-1$ has been created:

$Z_{k-1}-Z_{k} \geq 0 ; k=2,3, \ldots, m_{0}$

\subsection{Reconfiguration constraints}

An old block may be reused at maximum once:

$\sum_{q=1}^{q_{0}} B_{l q} \leq 1 ; \quad l=1,2, \ldots, l_{0}$

A new bloc may reuse an old bloc at maximum once:

$\sum_{l=1}^{l_{0}} B_{l q} \leq 1 ; \quad q=1,2, \ldots, q_{0}$

At least one old operation of block $l$ has to be assigned to new block $q$ to justify the reuse of block $l$ once:

$\sum_{i \in N_{l}} X_{i q} \leq B_{l q} ; \quad q=1,2, \ldots, q_{0} ; \quad l=1,2, \ldots, l_{0} ;$

\subsection{Goal constraints}

The aim of this study is to find an optimal solution that maximizes the reuse of the equipment from the initial line. We have two goals to achieve, the first is to obtain the same number of machines as in the initial line and the second is to reuse all blocks existing in the initial line. 
$\sum_{k=1}^{m_{0}} Z_{k}-m^{*}-d_{1}^{+}+d_{1}^{-}=0$

$\sum_{q=1}^{q_{0}} Y_{q}-\sum_{l=1}^{l_{0}} \sum_{q=1}^{q_{0}} B_{l q}+d_{2}^{+}-d_{2}^{-}=0$

where $\left(d_{1}^{-}, d_{1}^{+}\right)$and $\left(d_{2}^{-}, d_{2}^{+}\right)$are the negative and positive deviations of goals 1 and 2, respectively.

\subsection{Objective function}

The objective function for the reconfiguration problem of the transfer lines aims to minimize the changes in the initial line, i.e. the objective is to reuse all machines and all spindle heads. This objective is formulated as follows:

Minimize $\left(w_{1}\left(d_{1}^{-}, d_{1}^{+}\right)+w_{2}\left(d_{2}^{-}, d_{2}^{+}\right)\right)$;

where $w_{1}, w_{2}$ are the weights of goals 1 and 2, respectively, $w_{1}+w_{2}=1$.

In the next section, model (1) - (17) is evaluated in a numerical experiment.

\section{Experimental results}

To analyse the performance of the proposed model, a set of 41 problem instances inspired from real life industrial problems was solved by using ILOG 280 CPLEX 12.4 on PC Intel(R), $2.20 \mathrm{GHZ}$, with 8 Go RAM.

For all test instances, the number of operations $|N|$ was equal to 30 , the values of $m_{0}$ and $n_{0}$ were fixed to 10 and 4 , respectively. The desired line cycle time $T_{0}=100$ seconds.

Table 1. Results of tests for the proposed goal programming model

\begin{tabular}{lllllll}
\hline$w 1$ & $w 2$ & + +\#ts & +\#Blocks & \#Breused & Total blocks & Total time \\
\hline 0.1 & 0.9 & 17 & 14 & 154 & 168 & 3593.32 \\
0.2 & 0.8 & 16 & 18 & 151 & 169 & 4559.06 \\
0.3 & 0.7 & 16 & 16 & 150 & 166 & 3685.89 \\
0.4 & 0.6 & 16 & 14 & 152 & 166 & 3029.06 \\
0.5 & 0.5 & 14 & 19 & 152 & 174 & 2539.07 \\
0.6 & 0.4 & 10 & 20 & 153 & 173 & 1499.65 \\
0.7 & 0.3 & 9 & 14 & 152 & 166 & 1959.70 \\
0.8 & 0.2 & 10 & 14 & 152 & 166 & 1632.85 \\
0.9 & 0.1 & 10 & 21 & 151 & 172 & 1155.38 \\
\hline
\end{tabular}

The overall results for 41 test examples with different weights $w_{1}$ and $w 2$ used for goals 1 and 2 are reported in Table 1.

In this table, column "+\#Sts" represents the total number of extra workstations in comparison to the initial lines. Since all stations and spindle heads are modular, the reuse of a workstation is not restricted by the assignment of blocks, as a consequence, 
all workstations were reused in all reconfigurations. Columns "+\#Blocks" and "\#Breused" report respectively the total number of extra blocks and the number of old blocks that were reused in the new lines, for all 41 examples. Finally, columns "Total blocks" and "Time" present the total number of blocks for the old and new lines and the solution time (in seconds). Note that the "Total blocks" can be greater than the sum of "+\#Blocks" and "\#Breused", in this case, the new lines use less blocks than the old lines.

As expected, the choice of $w_{1}$ and $w_{2}$ is important for the evaluation of solutions. Since the workstations have less restrictions to be reused, lower values of $w_{1}$ lead to the growing number of extra workstations, but lower values of $w_{2}$ do not necessarily lead to the growing number of extra blocks.

The obtained results show that for the reconfiguration of the transfer line considered in this example with the hypotheses on the reusability of the equipment presented in this chapter, the best values of goal weights are: $w_{1}=0.7$ and $w_{2}=0.3$. It also can be noted that the problems with greater values of $w_{1}$ were generally solved faster.

Table 2 presents the detailed results of optimization for all 41 test examples for $w_{1}=0.7$ and $w_{2}=0.3$. In the table, \#Sts is the number of station in the reconfigured line, \#Blocks is the number of blocks in the reconfigured line, \%Blocks is the percentage of old blocks that were reused in the reconfigured line.

Table 2. Results of tests for 41 examples with $w 1=0.7$ and $w 2=0.3$

\begin{tabular}{|c|c|c|c|c|c|c|c|}
\hline Ex & \#Sts & $+\#$ Sts & \#Blocks & \#Breused & +\#Blocks & $\%$ Blocks & Calculation time \\
\hline 1 & 3 & 1 & 4 & 4 & 0 & 100 & 13.29 \\
\hline 2 & 3 & 0 & 4 & 3 & 1 & 100 & 122.88 \\
\hline 3 & 4 & 0 & 5 & 4 & 1 & 100 & 201.1 \\
\hline 4 & 3 & 0 & 4 & 3 & 1 & 100 & 34.52 \\
\hline 5 & 4 & 1 & 4 & 4 & 0 & 100 & 34.35 \\
\hline 6 & 3 & 0 & 3 & 3 & 0 & 100 & 3.24 \\
\hline 7 & 4 & 1 & 5 & 4 & 1 & 100 & 85.59 \\
\hline 8 & 4 & 1 & 4 & 4 & 0 & 100 & 97.14 \\
\hline 9 & 4 & 1 & 5 & 5 & 0 & 100 & 155 \\
\hline 10 & 3 & 0 & 4 & 4 & 0 & 100 & 56.25 \\
\hline 11 & 3 & 1 & 5 & 5 & 0 & 100 & 173.77 \\
\hline 12 & 4 & 1 & 4 & 4 & 0 & 100 & 36.84 \\
\hline 13 & 3 & 0 & 4 & 4 & 0 & 100 & 23.41 \\
\hline 14 & 3 & 1 & 4 & 4 & 0 & 100 & 16.06 \\
\hline 15 & 4 & 0 & 5 & 4 & 1 & 100 & 561.58 \\
\hline 16 & 3 & 0 & 4 & 4 & 0 & 100 & 4.47 \\
\hline 17 & 3 & 0 & 4 & 3 & 1 & 100 & 66.61 \\
\hline 18 & 3 & 0 & 4 & 4 & 0 & 100 & 34.16 \\
\hline 19 & 3 & 0 & 4 & 4 & 0 & 100 & 2.48 \\
\hline 20 & 4 & 0 & 4 & 4 & 0 & 100 & 4.43 \\
\hline 21 & 3 & 1 & 5 & 3 & 2 & 75 & 508.28 \\
\hline 22 & 3 & 1 & 3 & 3 & 0 & 75 & 22.3 \\
\hline 23 & 3 & 1 & 4 & 4 & 0 & 100 & 44.39 \\
\hline
\end{tabular}




\begin{tabular}{llllllll}
24 & 4 & 0 & 4 & 4 & 0 & 100 & 5.44 \\
25 & 3 & 0 & 3 & 3 & 0 & 100 & 64.91 \\
26 & 3 & 0 & 4 & 3 & 1 & 100 & 87.56 \\
27 & 3 & 0 & 3 & 3 & 0 & 100 & 8.98 \\
28 & 4 & 0 & 4 & 4 & 0 & 100 & 49.28 \\
29 & 4 & 1 & 5 & 5 & 0 & 100 & 81.82 \\
30 & 3 & 0 & 4 & 3 & 1 & 100 & 145.98 \\
31 & 3 & 0 & 4 & 4 & 0 & 100 & 5.39 \\
32 & 3 & 1 & 4 & 4 & 0 & 100 & 16.63 \\
33 & 3 & 0 & 5 & 3 & 2 & 100 & 221.95 \\
34 & 4 & 1 & 4 & 4 & 0 & 100 & 394.24 \\
35 & 3 & 1 & 3 & 3 & 0 & 75 & 17.47 \\
36 & 3 & 0 & 4 & 3 & 1 & 100 & 76.33 \\
37 & 3 & 0 & 4 & 3 & 0 & 75 & 3.3 \\
38 & 3 & 0 & 4 & 4 & 1 & 100 & 16.41 \\
39 & 3 & 0 & 4 & 4 & 0 & 100 & 7.39 \\
40 & 4 & 1 & 3 & 2 & 1 & 50 & 142.44 \\
41 & 3 & 0 & 4 & 3 & 1 & 100 & 39.23 \\
\hline
\end{tabular}

\section{Conclusion}

In this chapter, a goal programming model for the transfer line reconfigurations has been proposed. This problem arises when major changes affecting the characteristics of the production process occur. In such a situation, the line has to be reconfigured in order to meet the new production requirements minimizing the changes made in the line and reusing the existing equipment as much as possible.

The following hypotheses on the reusability of the equipment were assumed:

- operations can be removed and new operations can be added to an existing spindle head (block) if all compatibility constraints among machining operations are respected;

- all stations and spindle heads were considered as modular; thus, existing spindle heads could be removed from their initial workstation and installed at any workstation of the line.

The numerical experiment carried out for the evaluation of the goal programming approach showed that the obtained results strongly depend on the weights used in the model. The weights were attributed to the considered goals which were to reuse all workstations (goal 1) and all spindle heads (goal 2).

Future work may consider the integration in the proposed model of new constraints or goals in link with the environmental impact of the line reconfiguration, such as recycling of the obsolete equipment or evaluation of energy consumption of the reconfigured line, etc.

The approach and techniques proposed in this chapter can be used for a large spectrum of reconfigurable manufacturing systems. 
Another way for further research is to search for new techniques how design manufacturing systems which are able to produce different products from a given family without a costly and time consuming reconfigurations, see for example, recent publications (Battaïa et al., 2014ab, 2015, 2017ab; Kovalev et al., 2017) for reconfigurable rotary transfer machines.

\section{References}

Agpak K., Gokcen H. (2007) A chance-constrained approach to stochastic line balancing problem, Eur. J. Oper. Res., 180 (3), 1098-1115.

Altemeier S., Helmdach M., Koberstein A., Dangelmaier W. (2010) Reconfiguration of assembly lines under the influence of high product variety in the automotive industry-a decision support system, Int. J. Prod. Res., 48 (21), 6235-6256.

Battaïa O., Brissaud D., Dolgui A., Guschinsky N. (2015) Variety-oriented design of rotary production systems, CIRP Annals Manufact. Technol., 64(1), 411-414.

Battaïa O., Dolgui A. (2012) Reduction approaches for a generalized line balancing problem, Comput. and Oper. Res., 39, 2337-2345.

Battaïa O., Dolgui A., Guschinsky N. (2017a) Decision support for design of reconfigurable rotary machining systems for family part production, Int. J. Prod. Res., 55 (5), 1368-1385.

Battaïa O., Dolgui A., Guschinsky N., Levin G. (2012a) Optimal design of machines processing pipeline parts, Int. J. Adv. Manufact. Technol., 63, 963-973.

Battaïa O., Dolgui A., Guschinsky N., Levin G. (2012b) A decision support system for design of mass production machining lines composed of stations with rotary or mobile table, Robotics and Comput. Integr. Manufact., 28, 672-680.

Battaïa O., Dolgui A., Guschinsky N., Levin G. (2014a) Integrated configurable equipment selection and line balancing for mass production with serial-parallel machining systems, Engineering Optimization, 46 (10), 1369-1388

Battaïa O., Dolgui A., Guschinsky N., Levin G. (2014b) Combinatorial techniques to optimally customize an automated production line with rotary transfer and turrets, IIE Trans., 46, 867-879.

Battaïa O., Dolgui A., Guschinsky N. (2017b) Integrated process planning and system configuration for mixed-model machining on rotary transfer machine, Int. J. Comput. Integr. Manufact., 30 (9), 910-925.

Battaïa O., Gurevsky E., Makssoud F., Dolgui A. (2013) Equipment location in machining transfer lines with multi-spindle heads, J. Math. Modell. and Algor. in Oper. Res., 12 (2), 117-133.

Belmokhtar S., Dolgui A., Guschinsky N., Levin G. (2006) Integer programming models for logical layout design of modular machining lines, Comput. and Ind. Eng., 51 (3), 502-518.

Bukchin J., Tzur M. (2000) Design of flexible assembly line to minimize equipment cost, IIE Transactions, 32 (7), 585-598.

Choi G. (2009) A goal programming mixed-model line balancing for processing time and physical workload, Comput. \& Ind. Eng., 57 (1), 395-400.

Corominas A., Pastor R., Plans J. (2008) Balancing assembly line with skilled and unskilled workers, Omega, $36(6), 1126-1132$.

Deckro R., Rangachari S. (1990) A goal approach to assembly line balancing, Comput. and Oper. Res., 17 (5), 509-521.

Delorme X., Dolgui A., Kovalyov M. (2012) Combinatorial design of a minimum cost transfer line, Omega, 40 (1), 31-41.

Dolgui A., Finel B., Guschinskaya O., Guschinsky N., Levin G., Vernadat F., (2006a) Balancing largescale machining lines with multi-spindle heads using decomposition, Int. J. Prod. Res., 44 (18-19) 4105-4120.

Dolgui A., Finel B., Guschinsky N.N., Levin G. M., Vernadat F.B. (2006b) MIP approach to balancing transfer lines with blocks of parallel operations, IIE transactions, 38 (10), 869-882.

Dolgui A., Guschinsky N., Levin G. (2009) Graph approach for optimal design of transfer machine with rotary table, Int. J. Prod. Res., 47 (2), 321-341.

Dolgui A., Proth J.-M. (2006) Les systèmes de production modernes. Lavoisier : Londres. 
Dolgui A., Proth J.-M. (2010) Supply chain engineering: useful methods and techniques, Springer: London.

Essafi M., Delorme X., Dolgui A., Guschinskaya O. (2010) A MIP approach for balancing transfer lines with complex industrial constraints, Comput. and Ind. Eng., 58, 393-400.

Gadidov R., Wilhelm W. (2000) A cutting plane approach for the single-product assembly system design problem, Int. J. Prod. Res., 38 (8), 1731-1754.

Gamberini R., Grassi A., Rimini, B. (2006) A new multi-objective heuristic algorithm for solving the stochastic assembly line re-balancing problem, Int. J. Prod. Econ., 102 (2), 226-243.

Gamberini R., Gebennini E., Grassi A., Regattieri A. (2009) A multiple single-pass heuristic algorithm solving the stochastic assembly line rebalancing problem, Int. J. Prod. Res., 47 (8), 2141-2164.

Gokcen H., Agpak K. (2006) A goal programming approach to simple U-line balancing problem, Eur. J. Oper. Res., 171 (2), 577-585.

Gokcen H., Erel E. (1997) A goal programming approach to mixed-model assembly line balancing problem, Int. J. Prod. Econ., 24 (2), 177-185.

Gurevsky E., Battaïa O., Dolgui A., (2012) Balancing of simple assembly lines under variations of task processing times, Ann. Oper. Res., 201 (1), 265-286.

Gurevsky E., Battaïa O., Dolgui A. (2013a) Stability measure for a generalized assembly line balancing problem, Discr. Appl. Math., 161 (3), 377-394.

Gurevsky E., Hazir O., Battaïa O., Dolgui A., (2013b) Robust balancing of straight assembly lines with interval task times, J. Oper. Res. Soc., 64 (11), 1607-1613.

Guschinskaya O., Dolgui A. (2009) Comparison of exact and heuristic methods for a transfer line balancing problem, Int. J. Prod. Economics, 120 (2), 276-286.

Guschinskaya O., Dolgui A., Guschinsky N., Levin G. (2008) A heuristic multi- start decomposition approach for optimal design of serial machining lines, Eur. J. Oper. Res., 189 (3), 902-913.

Guschinskaya O., Dolgui A., Guschinsky N., Levin G. (2009) Minimizing makespan for multi-spindle head machines with a mobile table, Comput. and Oper. Res., 36 (2), 344-357.

Guschinskaya O., Gurevsky E., Dolgui A., Eremeev A. (2011) Metaheuristic approaches for the design of machining lines, Int. J. Adv. Manufact. Technol., 55 (2), 11-22.

Kara Y., Gokcen H., Atasagun Y. (2010) Balancing parallel assembly lines with precise and fuzzy goals, Int. J. Prod. Res., 48 (6), 1685-1703.

Kara Y., Paksoy T., Chang C.-T. (2009) Binary fuzzy goal programming approach to single model straight and U-shaped assembly line balancing, Eur. J. Oper. Res., 195 (2) 335-347.

Kara Y., Özgüven C., Seçme N., Chang C. (2011) Multi-objective approaches to balance mixed-model assembly lines for model mixes having precedence conflicts and duplicable common tasks, Int. J. Adv. Manufact. Technol., 52 (5-8), 725-737.

Kim G.C., Emery J. (2000) An application of zero-one goal programming in project selection and resource planning - a case study from the Woodward governor company, Comput. and Oper. Res., 27, 1389-1408.

Kimms A. (2000) Minimal investment budgets for flow line configuration, IIE Trans., 32, 287-298.

Kovalev S., Delorme X., Dolgui A., Oulamara A. (2017) Minimizing the number of stations and station activation costs for a production line, Comput. and Operat. Res., 79, 131-139.

Li S., Wang H., Hu S., Lin Y., Abell J. (2011) Automatic generation of assembly system configuration with equipment selection for automotive battery manufacturing, J. Manufact. Syst., 30 (4), 188195.

Makssoud F., Battaïa O., Dolgui A. (2014) An exact optimization approach for a transfer line reconfiguration problem, Int. J. Adv. Manufact. Technol., 72 (5-8), 717-727.

Makssoud F., Battaïa O., Dolgui A., Mpofu K., Olabanji O. (2015) Re-balancing problem for assembly lines: new mathematical model and exact solution method, Assembly Automation, 35 (1), 16-21.

Osman H., Baki M. (2014) Balancing transfer lines using benders decomposition and ant colony optimisation techniques, Int. J. Prod. Res., 52 (5,) 1334-1350.

Ozdemir R., Ayag Z. (2011) An integrated approach to evaluating assembly line design alternatives with equipment selection, Prod. Plan. and Contr., 22 (2), 194-206.

Ozcan U., Toklu B. (2009) Multiple-criteria decision-making in two-sided assembly line balancing: a goal programming and a fuzzy goal programming models, Comput. and Oper. Res., 36 (6), 19551965.

Pekin N., Azizoglu M. (2008) Bi-criteria flexible assembly line design problem with equipment decisions, Int. J. Prod Res., 46 (22), 6323-6343. 
Rossi A., Gurevsky E., Battaïa O., Dolgui A. (2016) Maximizing the robustness for simple assembly lines with fixed cycle time and limited number of workstations, Discr. Appl. Math., 208, 123-136.

Sotskov Y., Lai T.-C., Dolgui A. (2019) The stability radius of an optimal line balance with maximum efficiency for a simple assembly line, Eur. J. Oper. Res., 274, 466-481.

Toklu B., Özcan U. (2008) A fuzzy goal programming model for the simple U-line balancing problem with multiple objectives, Eng. Optim., 40 (3), 191-204.

Yoosefelahi A., Aminnayeri M., Mosadegh H., Davari Ardakahi H. (2012) Type II robotic assembly line balancing problem: An evolution strategies algorithm for a multi-objective model, J. Manufact. Syst., 31 (2), 139-151. 